\title{
DIMENSIONES BÁSICAS DEL DESARROLLO HUMANO: SALUD Y EDUCACIÓN EN LA PROVINCIA DEL CHACO, DIFERENCIAS TEMPORALES Y TERRITORIALES EN LAS ÚLTIMAS DÉCADAS
}

\author{
Mgtr. Vilma Lilian Falcón \\ Profesora Titular. Cátedra Geografía Económica y Política General \\ vfalcon 1609@hotmail.com \\ Dra. Mirta Liliana Ramirez \\ Profesora Titular. Cátedra Técnicas en Geografía II \\ liliana.ramirez.resistencia@gmail.com \\ Departamento de Geografía. Facultad de Humanidades. \\ Universidad Nacional del Nordeste
}

\section{RESUMEN}

Cuando el Programa de las Naciones Unidas para el Desarrollo (PNUD) definía a inicios de la década de los '90 al Desarrollo Humano, uno de los principales planteos del concepto aludía a la necesidad de brindar a la población mayores oportunidades de acceso a la educación, atención médica, ingreso, empleo, entre otros componentes de la dimensión del desarrollo humano. Hoy, pasada ya más de una década del nuevo siglo, queremos recuperar aquel concepto que entiende al Desarrollo como "el proceso de expansión de las capacidades de las personas que amplían sus opciones y oportunidades" y, entendiendo al proceso en término de tiempo, es esa temporalidad la que nos moviliza a "observar" cómo se dio la evolución de dos indicadores que refieren a dimensiones que consideramos fundamentales en la compleja trama del desarrollo humano: la educación y la salud de la población. En este sentido, es intención de este trabajo ofrecer una descripción del estado de situación de dos aspectos referidos a la educación y a la salud de la población chaqueña: el analfabetismo y la mortalidad infantil, aspectos que sin ser los únicos que debieran considerarse, por la ya comentada complejidad que encierra el concepto de Desarrollo Humano, resultan de importancia para el diagnóstico de aquellas situaciones que requieren de acciones para su corrección o mejora.

\section{PALABRAS CLAVES}

Desarrollo Humano; Educación; Salud, Analfabetismo; Mortalidad Infantil, Mortalidad Materna; Chaco

\section{BASIC DIMENSIONS OF HUMAN DEVELOPMENT: HEALTH AND EDUCATION IN THE PROVINCE OF CHACO, TEMPORARY AND TERRITORIAL DIFFERENCES IN RECENT DECADES}

\begin{abstract}
When the United Nations program for development (UNDP) defined at the beginning of the Decade of the ' 90 s to human development, one of the main schemes of the concept referred to the need to provide greater opportunities for access to education, health care, income, employment, among other components of the development dimension of the human population. Today, after more than one decade of the new century, want to recover that concept that understands development as "the process of expansion of the capabilities of the people who expand their options and opportunities", and understanding to the process in
\end{abstract}

Publicado en formato digital: Mgtr. Vilma Lilian Falcón y Dra. Mirta Liliana Ramirez. DIMENSIONES BÁSICAS DEL DESARROLLO HUMANO: SALUD Y EDUCACIÓN EN LA PROVINCIA DEL CHACO, DIFERENCIAS TEMPORALES Y TERRITORIALES EN LAS ÚLTIMAS DÉCADA Revista Geográfica Digital. IGUNNE. Facultad de Humanidades. UNNE. Año 12. № 23. Enero - Junio 2015. ISSN 1668-5180. Resistencia, Chaco. 
terms of time, is this temporality which mobilizes us to 'Watch' the evolution of two indicators referring to dimensions that we consider fundamental in the complex plot of human development was : the education and health of the population. In this sense, is this work intended to provide a description of the State of affairs of two aspects relating to education and the health of the Chaco population: illiteracy and infant mortality, aspects that without being the only ones that should be considered, complexity already commented that holds the concept of human development, are of importance for the diagnosis of situations requiring action for correction or improvement.

\section{KEY WORDS}

Human development; Education; Health, illiteracy; Infant mortality, Maternal Mortality; Chaco 
Revista Geográfica Digital. IGUNNE. Facultad de Humanidades. UNNE. Año 12. № 23.

Enero - Junio 2015. ISSN 1668-5180. Resistencia, Chaco

\section{Las dimensiones básicas del Desarrollo Humano}

El Programa de las Naciones Unidas para el Desarrollo (PNUD) planteó, a inicios de los '90, el concepto de "Desarrollo Humano", entendiéndose como el "proceso de ampliar la gama de opciones de las personas, brindándoles mayores oportunidades de educación, atención médica, ingreso y empleo, abarcando el espectro total de opciones humanas, desde su entorno físico en buenas condiciones hasta libertades económicas y políticas". (PNUD,1992). El cambio radical que implicó esta conceptualización de Desarrollo tuvo tal trascendencia en el mundo político, científico y en la sociedad en general que, pasado ya 25 año, no existen dudas del valioso aporte generado desde su aparición en el primer informe de las Naciones Unidas; precisamente desde esta organización se destaca que "el desarroIlo humano no se trata de un conjunto de preceptos fijos y estáticos, sino de un concepto en constante evolución, cuyas herramientas analíticas se adaptan a los cambios que ocurren en el mundo"(PNUD, 2010).

El Desarrollo Humano implica mayores oportunidades de las personas y pone énfasis en la libertad del ser humano para tener salud, educación y disfrutar de condiciones de vida dignas; pero también hace hincapié en que el desarrollo y el bienestar humano son mucho más que la suma de esas dimensiones y se traducen en un abanico más amplio de capacidades, que incluyen libertades, derechos y capacidades de interacción con otros (Cfr. PNUD, 2010). De allí que el concepto de Desarrollo Humano integra dimensiones que abarca a toda la persona por lo que adquiere características de multidimensional a lo que algunos autores añaden características de complejidad en un sentido sistémico dada las interacciones entre los variados factores (1) que interactúan en el proceso de desarrollo de la persona. (Cfr. Martinez Migueléz, M.2009).

Si bien hablamos de un concepto complejo, multidimensional, existen capacidades básicas que el desarrollo humano considera, por ejemplo, cuando se habla de oportunidades de las personas se supone que éstas pueden ser infinitas y cambiar con el tiempo, sin embargo el PNUD considera que "a todos los niveles de desarrollo, las tres más esenciales son disfrutar de una vida prolongada y saludable, adquirir conocimientos y tener acceso a los recursos para tener una vida decente. Si no se poseen estas oportunidades esenciales muchas otras alternativas seguirán siendo inaccesibles". De allí que en este trabajo se propone ofrecer una mirada a la evolución temporal de dos indicadores que refieren a las dimensiones salud y educación: el analfabetismo y la mortalidad infantil, tanto en su distribución temporal como territorial en el período 1990-2010.

En lo referente a la tasa de analfabetismo hemos adoptado este indicador de costo para exponer las condiciones de vulnerabilidad de la población y el territorio que habita, en concordancia con la conceptualización que realiza Katzman, 1999 (2), quien señala que la vulnerabilidad a la que se encuentran expuestos los analfabetos afecta su autoestima y aumenta la probabilidad de que tengan sentimientos de riesgo, inseguridad e indefensión, todo lo cual restringe su capacidad de respuesta individual y de beneficiarse de las opciones que le ofrecen la sociedad y las organizaciones sociales para hacer frente a dicho riesgo. En resumen, las personas analfabetas son más vulnerables por ambos componentes, tienen mayores riesgos y menor capacidad de respuesta.

Por otro lado, los datos sobre mortalidad miden sólo un aspecto, si bien dramático, del bienestar. Sin embargo, sobrevivir es apenas uno de los factores involucrados en llevar una vida larga y saludable. La mortalidad infantil, por su parte, constituye un aspecto destacado dentro de la realidad de nuestro tiempo y, en países subdesarrollados, es un problema importante para el sector salud; se relaciona con numerosas causas de orden social, económico, demográfico, pues comprende una edad muy vulnerable a las agresiones

Publicado en formato digital: Mgtr. Vilma Lilian Falcón y Dra. Mirta Liliana Ramirez. DIMENSIONES BÁSICAS DEL DESARROLLO HUMANO: SALUD Y EDUCACIÓN EN LA PROVINCIA DEL CHACO, DIFERENCIAS TEMPORALES Y TERRITORIALES EN LAS ÚLTIMAS DÉCADA Revista Geográfica Digital. IGUNNE. Facultad de Humanidades. UNNE. Año 12. № 23. Enero - Junio 2015. ISSN 1668-5180. Resistencia, Chaco.

En: http://hum.unne.edu.ar/revistas/geoweb/default.htm 
biológicas que se originan en un ambiente físico desfavorable, las que provocan enfermedades que se manifiestan en el primer año de vida y pueden ser evitables total o parcialmente (Cfr. Ramirez, L.1997:138).

Tanto la tasa de analfabetismo como la de Mortalidad Infantil constituyen indicadores que, en general, han ido descendiendo en todo el mundo y ello se releja en los indicadores e informes como los de las Organización Mundial de la salud (OMS) (3), del PNUD o de la propia Naciones Unidas (4), entre otros. En el caso de Argentina se da la particularidad de que tanto en salud como en educación, algunos indicadores revelan características de países desarrollados (Tasa de matriculación primaria, Esperanza de vida, reducción de Mortalidad por causas no transmisibles, por ejemplo); sin embargo, otros dejan ver que aún queda mucho por hacer en materia sanitaria y educativa, especialmente para reducir las brechas territoriales en el país y al interior de las provincias.

Reconocer los logros operados en el territorio y en la sociedad que habita esos territorios es sin dudas la parte más gratificante de un estado de diagnóstico tendiente a evaluar los efectos de las políticas públicas aplicadas por los gobiernos en un determinado tiempo, pero, al mismo tiempo, requiere reconocer aquellos desajustes y situaciones indeseables que con el paso del tiempo persisten como condiciones desequilibrantes tanto por lo que implica para cada individuo y sociedad a la que pertenece como por la configuración territorial que adquieren esas condiciones.

En este sentido, es intención de este trabajo ofrecer una descripción del estado de situación de dos aspectos referidos a la educación y a la salud de la población chaqueña: el analfabetismo y la mortalidad infantil, aspectos que sin ser los únicos que debieran considerarse, por la ya comentada complejidad que encierra el concepto de Desarrollo Humano, resultan de importancia para el diagnóstico de aquellas situaciones que requieren de acciones para su corrección o mejora.

Para llevar adelante el análisis de los indicadores que se muestran en este trabajo nos basamos en los datos provenientes del Instituto Nacional de Estadística y Censo (INDEC) a través de los Censos Nacionales de 1991, 2001 y 2010 y de las Estadísticas Vitales de la provincia del Chaco y de las Estadísticas Vitales y Sanitarias proporcionadas por la Dirección de Bioestadística del Ministerio de Salud de la Provincia del Chaco.

\section{1.- La dimensión Educación}

\section{2.-Evolución de la Tasa de Analfabetismo en Argentina}

En estudios previos realizados en la década de los '90(5) hacíamos referencia al sostenido retroceso que experimentaba el analfabetismo en el país a la vez que marcábamos la notable diferencia existente entre las distintas provincias y regiones. Hoy, a 25 años de aquellas observaciones, podemos referirnos con las mismas palabras a la situación educativa de Argentina, al menos en lo que se refiere a las condiciones de analfabetismo de su población.

Según el Programa de las Naciones Unidas para el Desarrollo (PNUD), las tasas de analfabetismo de la Argentina son de las más bajas entre los países latinoamericanos, destacando al período intercensal 1980-1991 como la mayor variación de las últimas cuatro décadas, situación que se refleja muy claramente en el Grafico № 2 de la página siguiente.

A los efectos de observar un período mayor para analizar la situación del país incorporamos los datos del período 1970-2010, lapso en el que se puede advertir que la tasa de analfabetismo de la población de más de 10 años registra una disminución sostenida pasando del 7,4\% en 1970 al 3,7 \% en 1980 y, aunque la reducción se mantuvo entre 2001

Publicado en formato digital: Mgtr. Vilma Lilian Falcón y Dra. Mirta Liliana Ramirez. DIMENSIONES BÁSICAS DEL DESARROLLO HUMANO: SALUD Y EDUCACIÓN EN LA PROVINCIA DEL CHACO, DIFERENCIAS TEMPORALES Y TERRITORIALES EN LAS ÚLTIMAS DÉCADA Revista Geográfica Digital. IGUNNE. Facultad de Humanidades. UNNE. Año 12. № 23. Enero - Junio 2015. ISSN 1668-5180. Resistencia, Chaco. 
y 2010, lo hizo en forma menos vertiginosa tal como se puede observar en los Gráficos de la página siguiente.
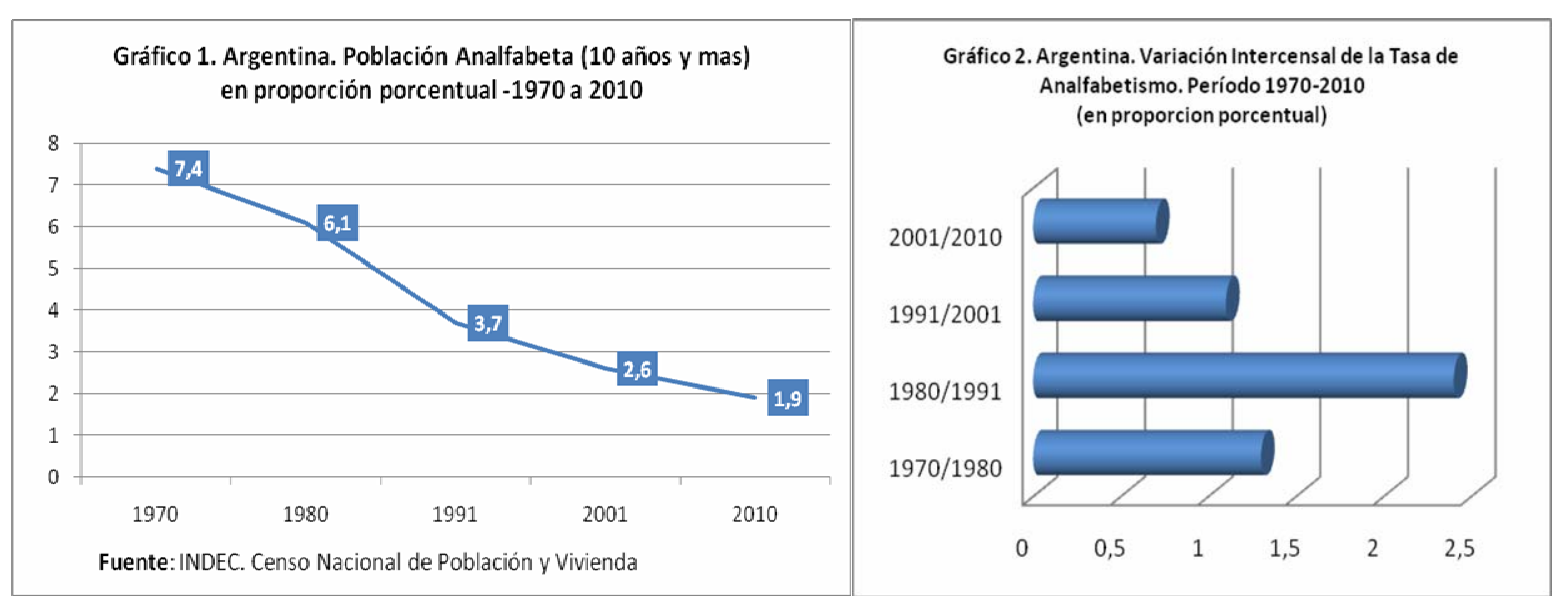

En el Informe Mundial del año 2010 (6) el PNUD señala que en el mundo "Los avances en educación han sido sustanciales y generalizados y reflejan mejoras cuantitativas en escolaridad y en igualdad de acceso para ambos sexos [...] Las tasas de alfabetismo, por su parte, han crecido de $73 \%$ a $84 \%$ y no han disminuido en ningún país [...] En todo el mundo, las personas hoy tienen el mayor nivel de educación de la historia y este resultado es válido para muchas mediciones diferentes."

Como lo señaláramos, resulta innegable el progreso educativo para nuestro país pero, al mismo tiempo, no podemos dejar de considerar que los promedios nacionales ocultan marcadas diferencias regionales que se reflejan en la distribución geográfica de los
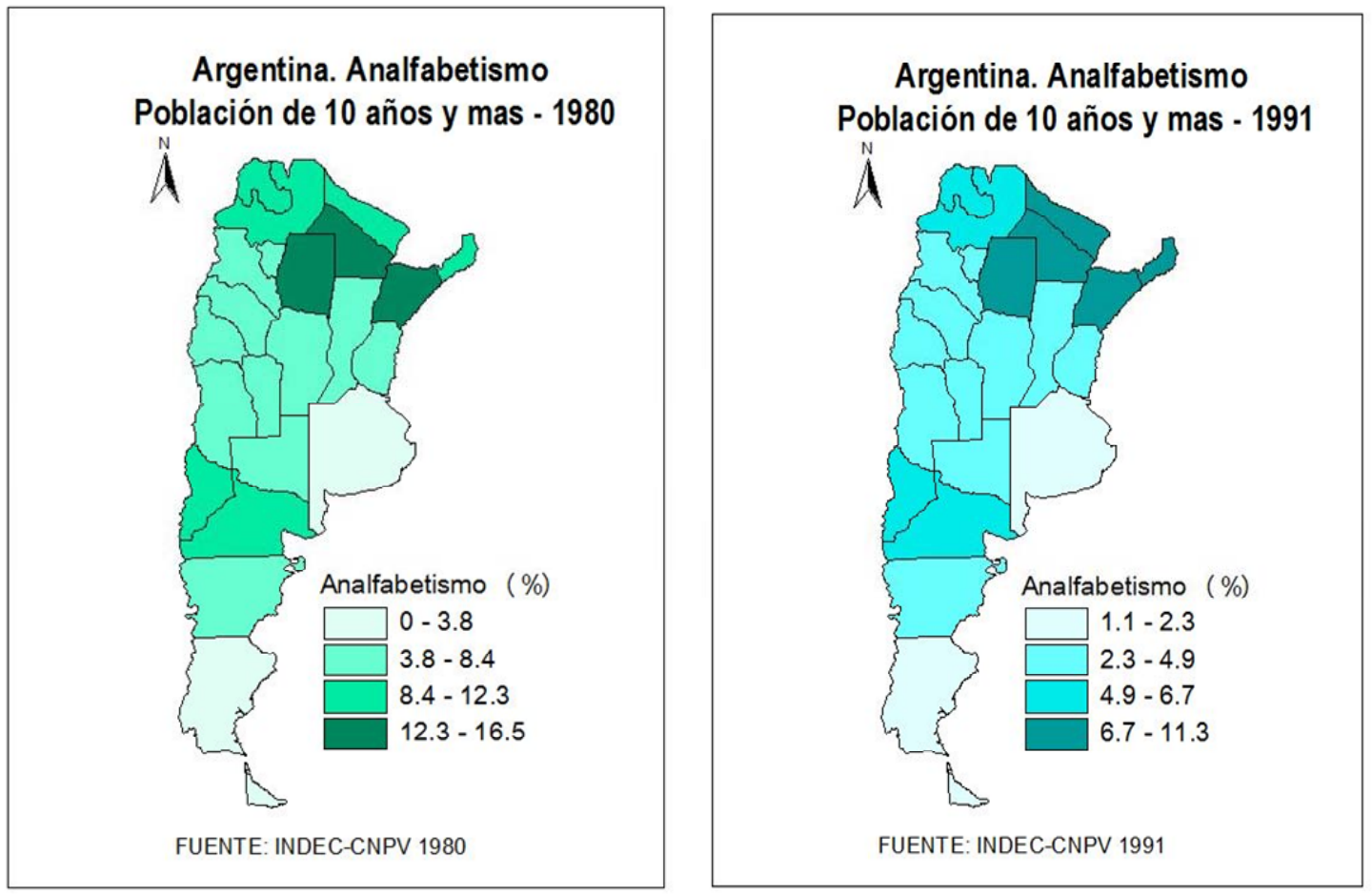

valores de analfabetismo de cada provincia. Como se observa en la secuencia de mapas, especialmente si se presta atención a los valores máximos representados en cada uno de ellos, las condiciones de analfabetismo de la población mayor a diez años en las provincias

Publicado en formato digital: Mgtr. Vilma Lilian Falcón y Dra. Mirta Liliana Ramirez. DIMENSIONES BÁSICAS DEL DESARROLLO HUMANO: SALUD Y EDUCACIÓN EN LA PROVINCIA DEL CHACO, DIFERENCIAS TEMPORALES Y TERRITORIALES EN LAS ÚLTIMAS DÉCADA Revista Geográfica Digital. IGUNNE. Facultad de Humanidades. UNNE. Año 12. № 23. Enero - Junio 2015. ISSN 1668-5180. Resistencia, Chaco.

En: http://hum.unne.edu.ar/revistas/geoweb/default.htm 
muestran una progresiva disminución década tras década aunque ello no oculta la notoria brecha existente entre ellas.
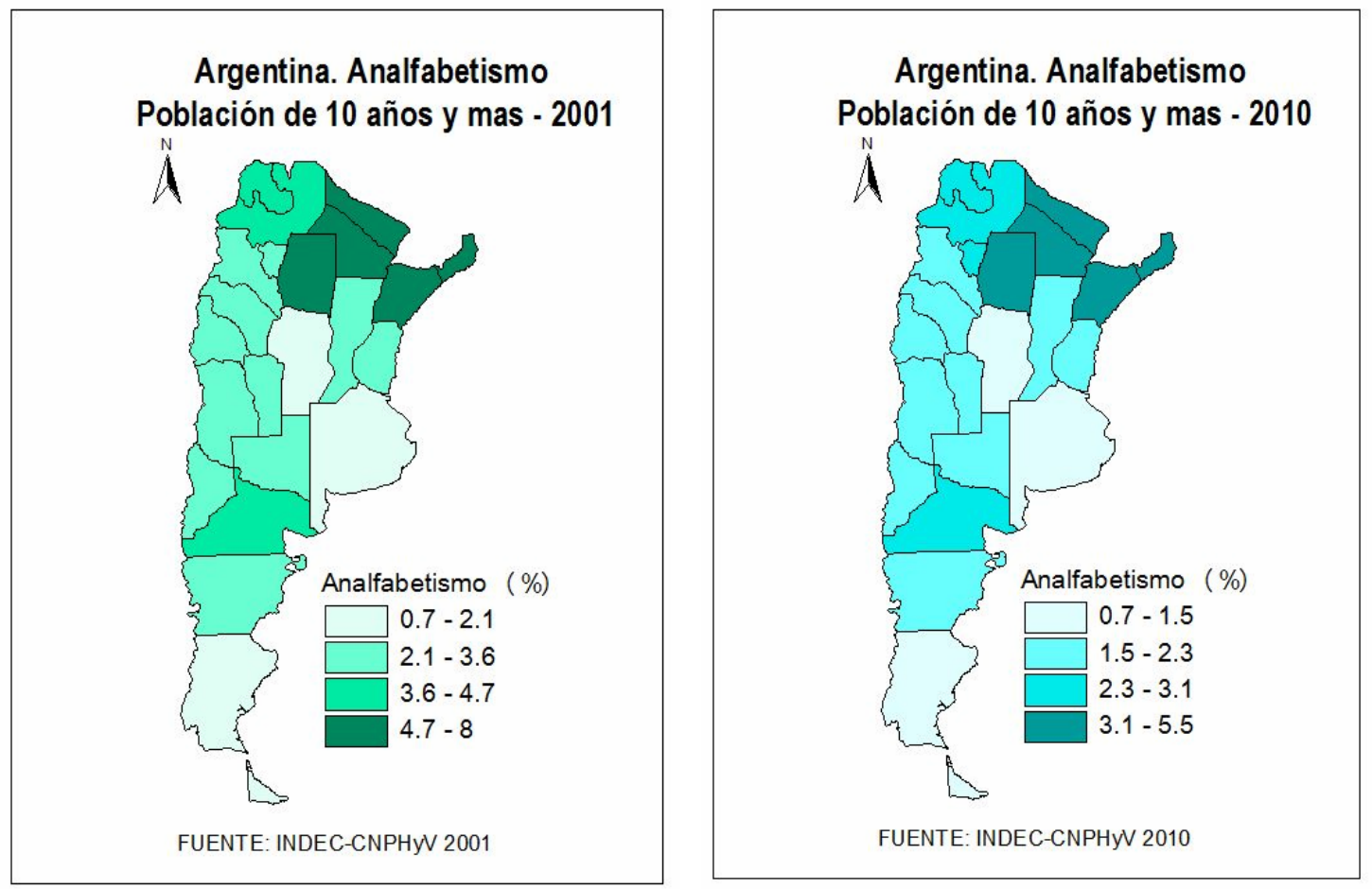

En nuestro caso particular nos interesa destacar la situación de las provincias del Nordeste y entre ellas al Chaco, unidad político administrativa que a pesar de los progresos en materia de educación continuó a la vanguardia como provincia con las mayores tasas de población analfabeta en el país.

\section{2.-El Analfabetismo en el NEA y provincia del Chaco}

El gráfico $\mathrm{N}^{\circ} 3$ muestra las condiciones de analfabetismo en las cuatro provincias que forman la región del NEA y el dinamismo que se dio entre 1980 y 2010, situación que se

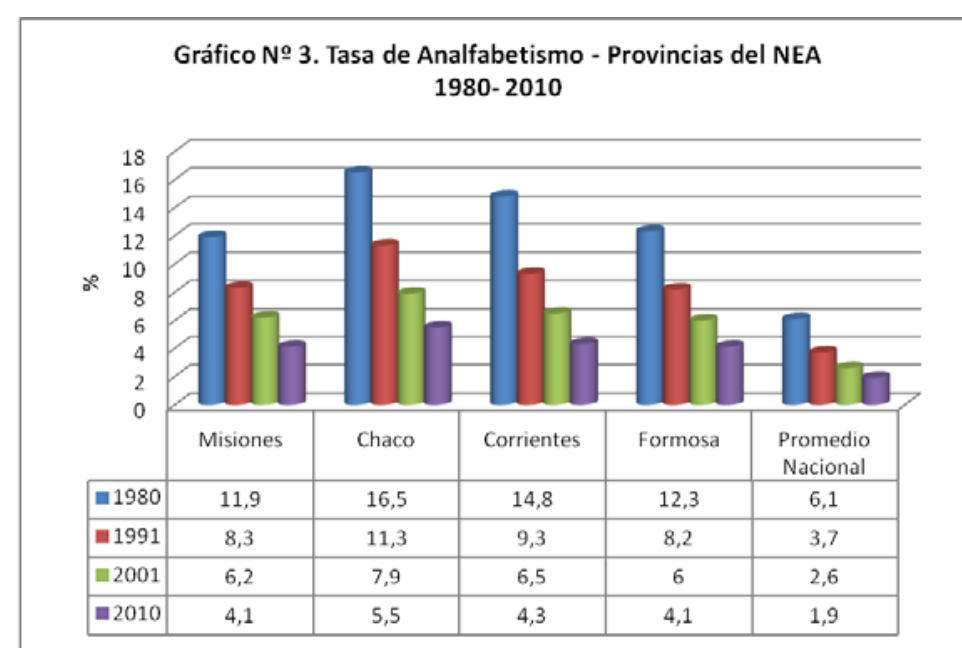
condice con el progreso educativo nacional que mencionamos anteriormente. No obstante, cabe una observación respecto de la provincia del Chaco: hacia el año 1991 era el único distrito en el país y región que no había podido hacer descender su tasa de analfabetismo a valores de un dígito. Según los datos del Censo Nacional de Población y Vivienda (CNVP) de 1991, el 11,3\% de analfabetismo representaba tres veces el promedio nacional y 16 veces más si se comparaba con las cifras correspondientes a otros

Publicado en formato digital: Mgtr. Vilma Lilian Falcón y Dra. Mirta Liliana Ramirez. DIMENSIONES BÁSICAS DEL DESARROLLO HUMANO: SALUD Y EDUCACIÓN EN LA PROVINCIA DEL CHACO, DIFERENCIAS TEMPORALES Y TERRITORIALES EN LAS ÚLTIMAS DÉCADA Revista Geográfica Digital. IGUNNE. Facultad de Humanidades. UNNE. Año 12. № 23. Enero - Junio 2015. ISSN 1668-5180. Resistencia, Chaco. 
distritos del país como por ejemplo el de Capital Federal que registraba un $0,7 \%$ de población analfabeta para esa época censal. Aún así, analizando los datos del período que va desde 1991 al año 2010 no se puede negar que los avances cuantitativos en materia de alfabetización de la población chaqueña resultan significativos, a tal punto que merece destacarse que en el conjunto del Nordeste es la provincia que más redujo sus tasas, situación que se puede advertir en el gráfico que muestra las distancias intercensales para cada provincia del NEA.

Tasa de Analfabetismo - 1991-2010

Distancias intercensales

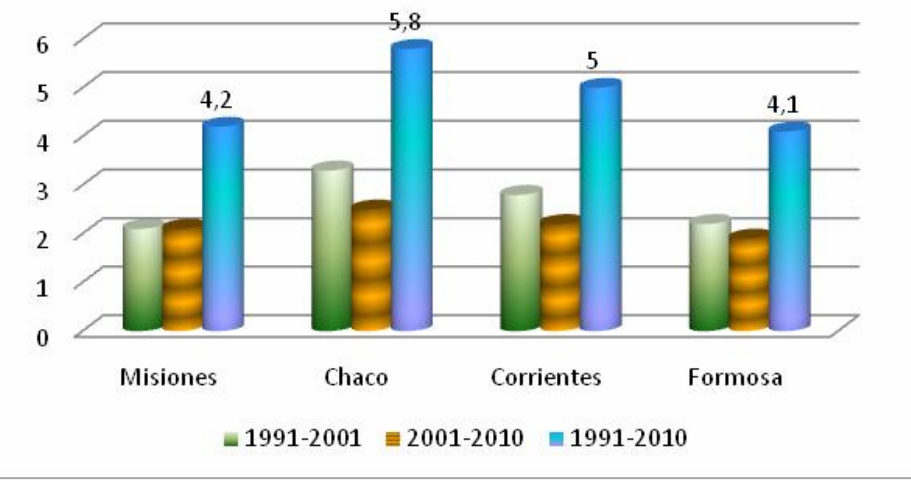

En la provincia del Chaco se reproduce, de algún modo, la situación nacional en tanto podemos afirmar que estos logros se dan en forma diferenciada en el territorio, resultando un espacio que se manifiesta con

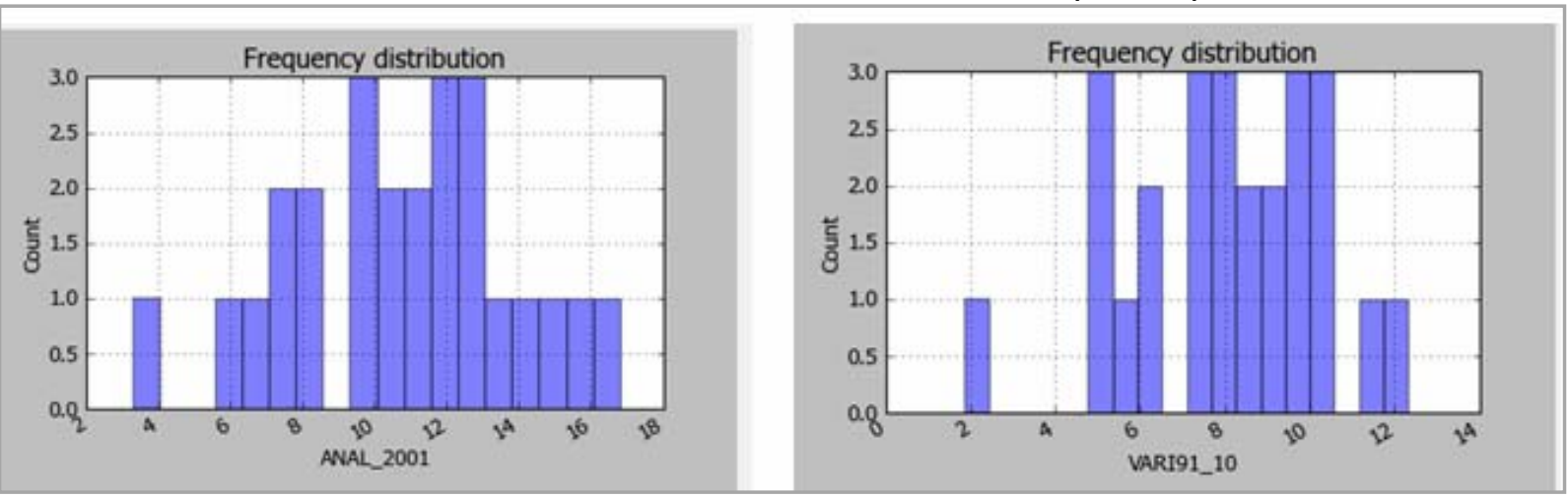

desequilibrios en la distribución geográfica tanto de las tasas de analfabetismo del período considerado como de los porcentuales que indican la variación intercensal 19912001.

Un análisis estadístico sencillo permite corroborar esta afirmación ya que, como se puede advertir, en los gráficos de distribución de frecuencia de las dos variables consideradas, el modo en que se agrupan las unidades administrativas en función de sus valores, situación que en este caso revela una distribución heterogénea en el territorio.

En el mapa $N^{\circ} 1$ se representó la diferencia intercensal de ese período para cada unidad administrativa, pudiéndose advertir las desigualdades en el ritmo de variación. En algunos Departamentos la reducción de las tasas de analfabetismo

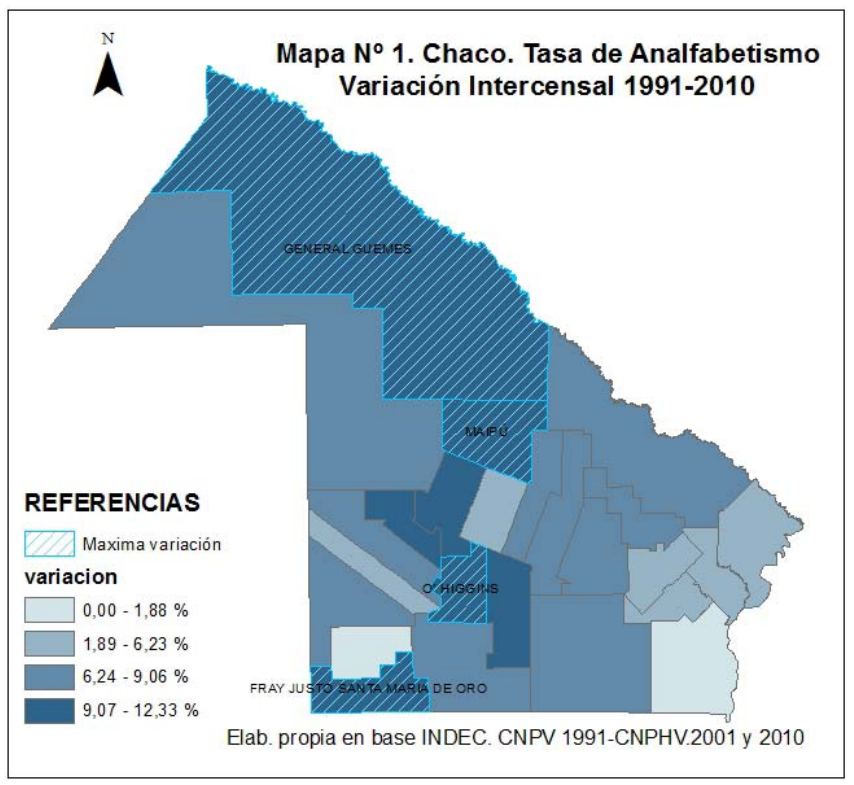


de la población mayor a 10 años es significativa, llegando a valores próximos al $13 \%$ tal es el caso de General Güemes, Maipú, O’Higgins y Fray J. Sta. María de Oro, resaltados en la cartografía. Esta situación adquiere mayor relevancia si consideramos que se trata de unidades administrativas que desde años atrás vienen ostentando los peores índices de analfabetismo.

\subsubsection{La situación en el año 2001}

Hacia el año 2001 el Chaco conservaba su posición en el ranking nacional como distrito con la mayor tasa de analfabetismo (7,98\%) a la vez que mantenía las disparidades al interior de su territorio, como se observa en el mapa $\mathrm{N}^{0} 2$.

Departamentos como General Güemes presentaban valores cercanos al $17 \%$ de población analfabeta mientras que otros como San Fernando -distrito en el que se asienta la ciudad Capital- llegaba al 3.3\%. Precisamente, en la siguiente imagen se muestra, a través de un diagrama de caja el resultado del análisis estadístico a través del cual quedan expuestos los casos extremos; por un lado, la situación más crítica de una entidad territorial $\mathrm{y}$, por otro, lo que podría considerarse como la mejor situación, ambos resaltados en el diagrama y mapa resultante.
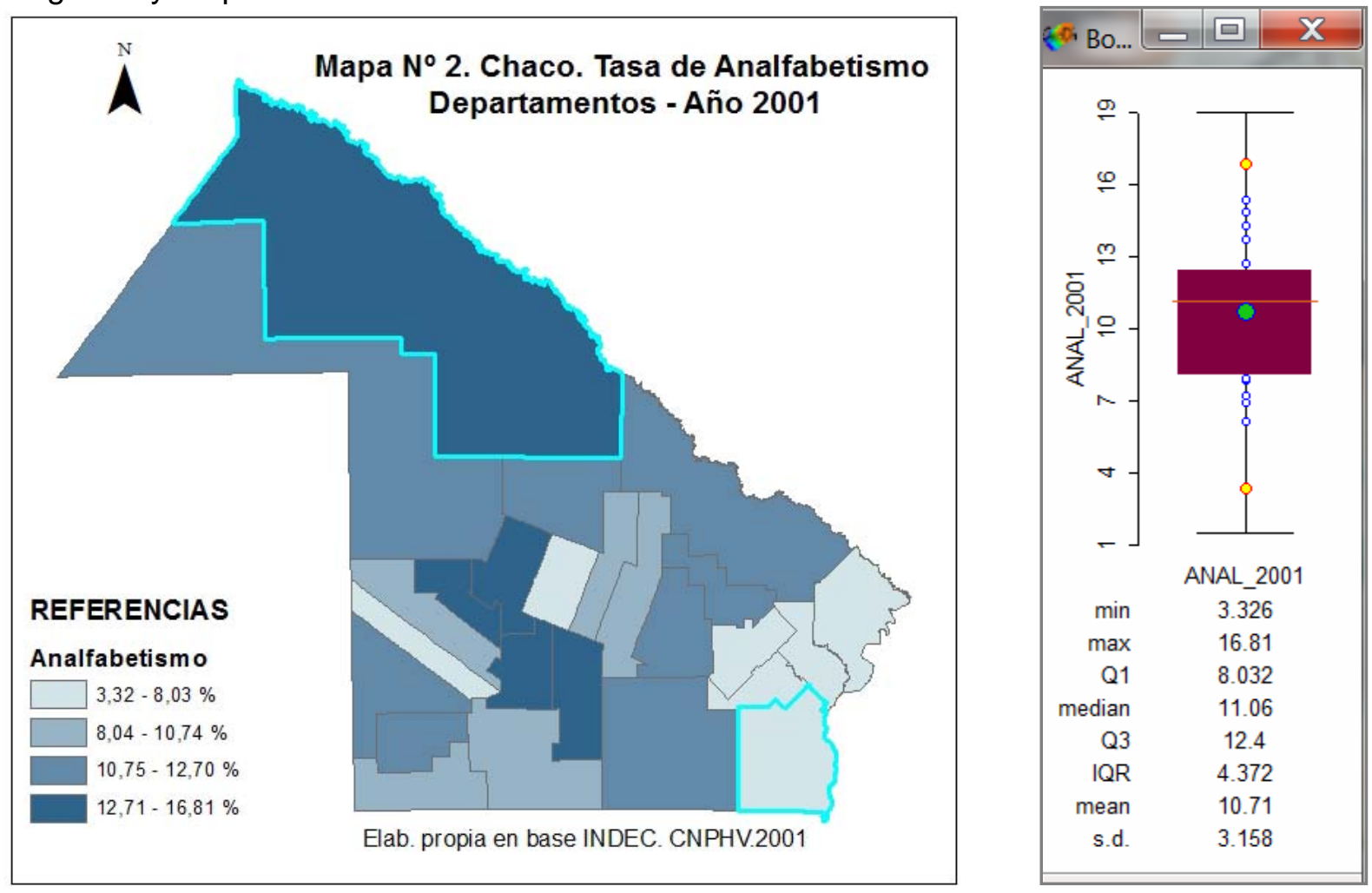

\subsubsection{Las condiciones en la década de 2010}

Si bien en la última década no se logró homogeneizar los niveles de analfabetismo en el territorio provincial todos los departamentos redujeron sus valores, destacándose General Güemes, Independencia, San Lorenzo y O'Higgins con mayores amplitudes en las reducciones porcentuales de población en esta condición, aunque continúan con tasas cercanas al 10\% formando parte del conjunto de 17 Departamentos con valores críticos y cuyos valores se encuentran por encima del promedio provincial que es de

Publicado en formato digital: Mgtr. Vilma Lilian Falcón y Dra. Mirta Liliana Ramirez. DIMENSIONES BÁSICAS DEL DESARROLLO HUMANO: SALUD Y EDUCACIÓN EN LA PROVINCIA DEL CHACO, DIFERENCIAS TEMPORALES Y TERRITORIALES EN LAS ÚLTIMAS DÉCADA Revista Geográfica Digital. IGUNNE. Facultad de Humanidades. UNNE. Año 12. № 23. Enero - Junio 2015. ISSN 1668-5180. Resistencia, Chaco. 
$5.48 \%$. En el otro extremo, al grupo de departamentos con valores inferiores a la media provincial (7) se incorporó General Dónovan que redujo su tasa de analfabetismo de 8,03\% a $4,92 \%$.

A través del gráfico $N^{\circ} 5$, de la página siguiente, se muestra la situación de cada Departamento en relación al promedio provincial, representándose además la línea que corresponde al valor medio del país el que, para 2010, correspondió a un $1.98 \%$ de población analfabeta.
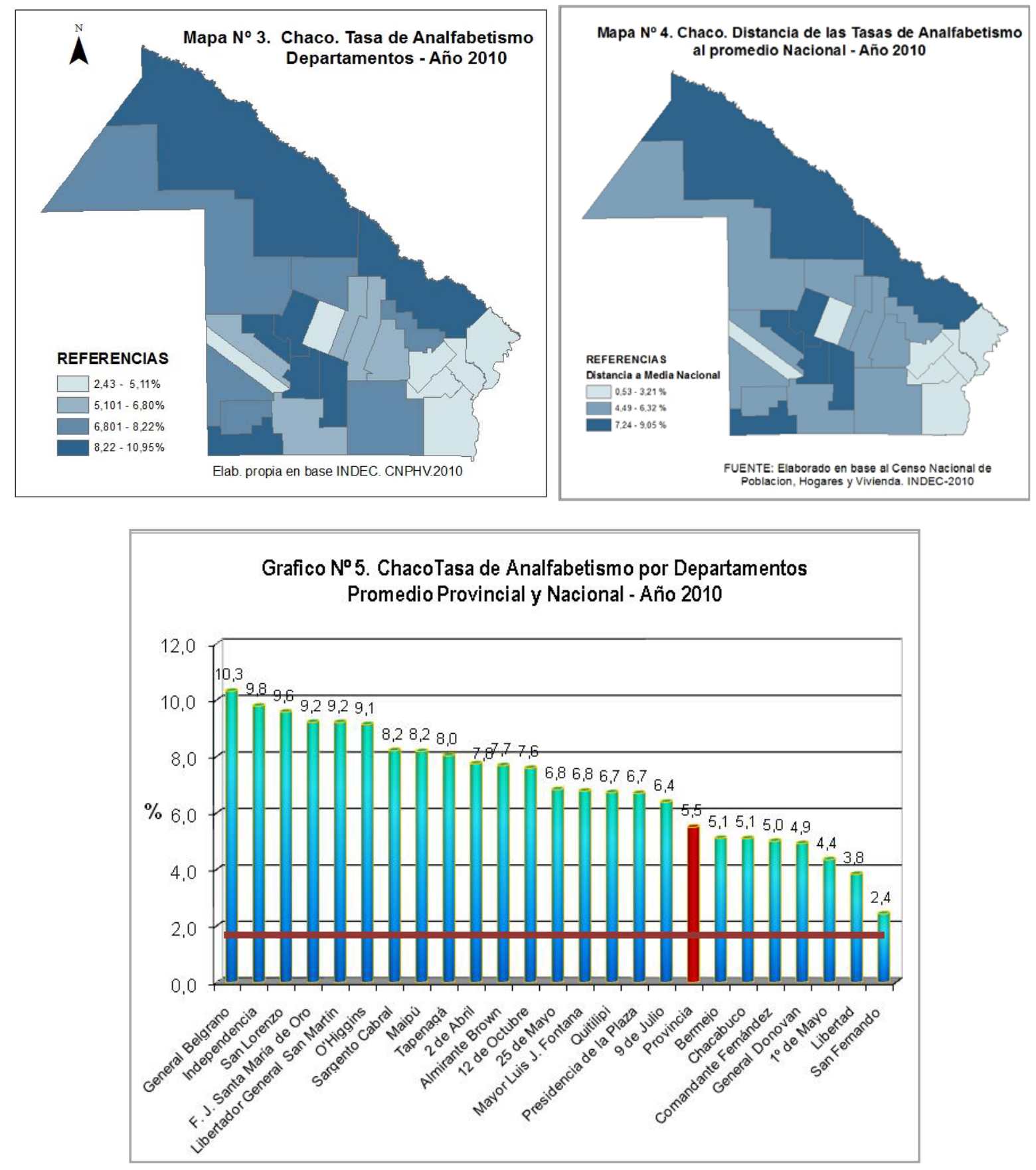

Publicado en formato digital: Mgtr. Vilma Lilian Falcón y Dra. Mirta Liliana Ramirez. DIMENSIONES BÁSICAS DEL DESARROLLO HUMANO: SALUD Y EDUCACIÓN EN LA PROVINCIA DEL CHACO, DIFERENCIAS TEMPORALES Y TERRITORIALES EN LAS ÚLTIMAS DÉCADA Revista Geográfica Digital. IGUNNE. Facultad de Humanidades. UNNE. Año 12. № 23. Enero - Junio 2015. ISSN 1668-5180. Resistencia, Chaco.

En: http://hum.unne.edu.ar/revistas/geoweb/default.htm 
Hacemos referencia al promedio nacional dado que podría constituirse en un punto de referencia para medir el logro de la situación educativa en los próximos años o década. En ese sentido, podría ser útil preguntarse ¿qué distancia separa a las unidades departamentales de ese objetivo?. Para obtener una respuesta se propone observar la distancia -en valores porcentuales- que presenta cada Departamento de la provincia al valor actual promedio del país situación que se refleja en el gráfico y en el mapa $\mathrm{N}^{0} 4$.

Como sabemos, las unidades censales tienen valor como entidades para el relevamiento estadístico pero no cuentan con funciones de gobierno y decisiones de orden político territorial, atribuciones que si lo tienen las entidades municipales; es por ello que incorporamos un mapa con los valores de analfabetismo distribuidos según radio censal para el año 2010 (8) junto con las divisiones administrativas correspondiente a los municipios de la provincia, de este modo puede apreciarse con mayor detalle las condiciones al interior de cada municipio. Por otra parte se destacan, como resultado del análisis del diagrama de caja, los espacios que presentan las condiciones más críticas, cuyos valores superan al $20 \%$ de población mayor a 10 años analfabeta, espacios que ameritan ser tenidos en cuenta en el diseño de las políticas públicas cuyo objetivos apunten a disminuir las desventajas en las que se encuentra la población de esos territorios.
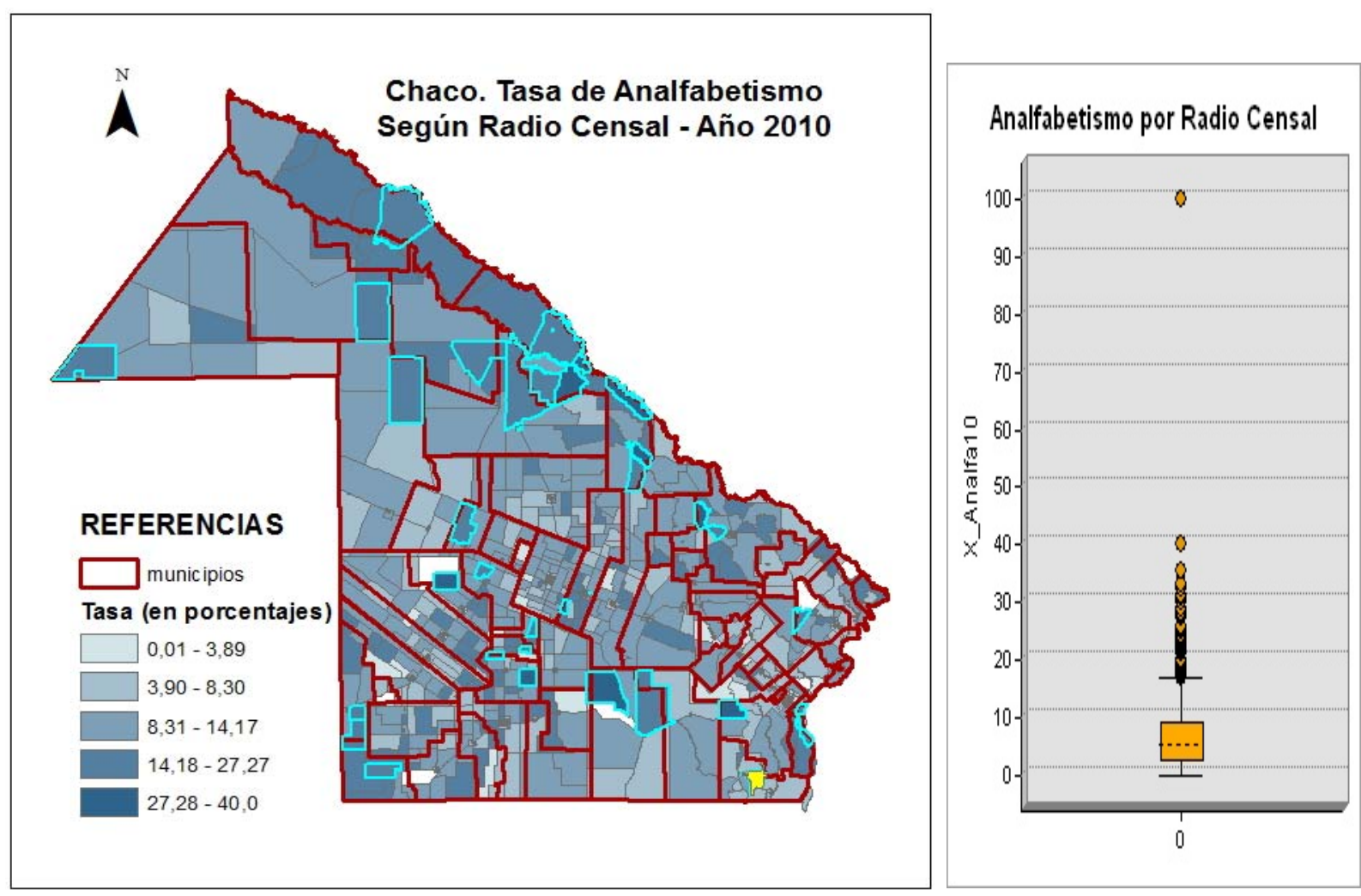

Como resultado del análisis podemos señalar que de las 1438 unidades censales 41 de ellas forman parte del grupo con mayores niveles de analfabetismo. Se trata de radios censales que registran un total de 2267 personas que presentan condiciones críticas de alfabetización y cuyos niveles oscilan entre $20 \%$ y $100 \%$, lo que arroja un promedio de $26,9 \%$, valores que sitúan temporalmente a estos territorios a las condiciones que presentaba la provincia por lo menos unos 50 años atrás. Exceptuando el caso extremo que aparece en el gráfico (9), los radios censales tienen una mayor concentración en el rango de

Publicado en formato digital: Mgtr. Vilma Lilian Falcón y Dra. Mirta Liliana Ramirez. DIMENSIONES BÁSICAS DEL DESARROLLO HUMANO: SALUD Y EDUCACIÓN EN LA PROVINCIA DEL CHACO, DIFERENCIAS TEMPORALES Y TERRITORIALES EN LAS ÚLTIMAS DÉCADA Revista Geográfica Digital. IGUNNE. Facultad de Humanidades. UNNE. Año 12. № 23. Enero - Junio 2015. ISSN 1668-5180. Resistencia, Chaco. 
$20 \%$ a $40 \%$ de analfabetismo, valores que distan entre cuatro y ocho veces más del promedio provincial.

Con el objetivo de aportar mayores detalles de estos espacios se muestra el resultado de la superposición de los mapas en la tabla № 1 de la siguiente página.

\begin{tabular}{|c|c|c|c|}
\hline Departamento & Municipio & $\begin{array}{c}\text { Radio Censal (CNPHV- } \\
\text { 2010) con Analfabetismo } \\
\text {, } 20 \%\end{array}$ & $\begin{array}{l}\text { Población } \\
\text { cantidad }\end{array}$ \\
\hline \multirow{5}{*}{ Gral. Güemes } & El Sauzalito & 1 & 53 \\
\hline & Fuerte Esperanza & 1 & 9 \\
\hline & Miraflores & 2 & 249 \\
\hline & Va. Río Bermejito & 5 & 354 \\
\hline & J.J. Castelli & 3 & 400 \\
\hline \multirow[b]{2}{*}{ Gral. San Martín } & Pampa del Indio & 3 & 929 \\
\hline & Gral. San Martin & 2 & 14 \\
\hline \multirow{3}{*}{ Almirante Brown } & Taco Pozo & 1 & 24 \\
\hline & Los Frentones & 1 & 16 \\
\hline & C. del Bermejo & 1 & 18 \\
\hline Gral. Belgrano & Corzuela & 1 & 3 \\
\hline Campo Largo & Campo Largo & 2 & 51 \\
\hline \multirow{3}{*}{ O’Higgins } & La Clotilde & 1 & 25 \\
\hline & La Tigra & 1 & 24 \\
\hline & San Bernardo & 2 & 18 \\
\hline Tapenagá & Charadai & 2 & 46 \\
\hline \multirow[b]{2}{*}{ Fray Justo S.M. de Oro } & Chorotis & 1 & 13 \\
\hline & Sta. Silvina & 1 & 8 \\
\hline 12 de Octubre & Gancedo & 2 & 15 \\
\hline Quitilipi & Quitilipi & 2 & 15 \\
\hline \multirow{4}{*}{ San Fernando } & Resistencia & 1 & 2 \\
\hline & Basail & 1 & 2 \\
\hline & Barranqueras & 1 & 4 \\
\hline & Vilelas & 1 & 8 \\
\hline \multirow{3}{*}{ Bermejo } & Puerto Bermejo & 1 & 4 \\
\hline & La leonesa & 1 & 16 \\
\hline & & 41 & 2267 habitan \\
\hline
\end{tabular}

Tabla N 1.- Elaboración propia en base a datos del CNPHV 2010 - según Radios Censales

En el mundo entero, tratados y leyes reconocen que la educación es un derecho humano fundamental; si a esto se añade que la educación provee conocimientos y competencias que permiten a las personas desarrollar plenamente su potencial, se convierte en un factor fundamental para alcanzar los demás objetivos de desarrollo.

Sabemos que evaluar las condiciones de la educación de una sociedad mirando solo un indicador -como en este caso - deja de lado muchos otros posibles análisis e interpretaciones de la realidad pero, aún así, creemos que estimar la cantidad de población que no sabe leer ni escribir y revelar en qué parte del territorio se encuentran quienes padecen estas condiciones más desfavorables puede constituirse en el punto inicial de otros estudios más complejos que revelen con mayor claridad dónde y con qué grado de 
urgencia se necesita la aplicación de políticas que ayuden a minimizar esas condiciones de riesgo.

\section{2.- La dimensión Salud}

\section{1.-Evolución de la Mortalidad Infantil en Argentina}

Abonando lo que se ha señalado en la introducción la mortalidad infantil, tanto como hecho demográfico propiamente dicho así como por ser un indicador del desarrollo económico y social de las regiones, los países, las provincias o municipios, ha sido -y estema de estudio de investigaciones y ensayos de diferentes disciplinas científicas. La Geografía, la Demografía y la Medicina, entre otras, cada una de ellas desde su mirada particular, han aportado muy valiosa información, conocimiento y saber que a lo largo del tiempo se tradujo en políticas, programas o estrategias de gestión conducentes a atenuar, y en el mejor de los casos, a eliminar las desigualdades territoriales que este indicador manifiesta. Sin embargo, este último propósito perseguido constantemente por las gestiones de gobierno y apoyado por los avances en los conocimientos médicos y por las investigaciones científicas, no siempre tiene su correlato con la realidad.

Al igual que lo mencionáramos en el caso de las tasas de analfabetismo, descripta en párrafos anteriores, la tendencia descendente opera como un indicador de beneficio pero no se debe dejar de considerar que se da en un contexto de reducción que operó en todo el mundo por lo que resulta necesario observar cuales son las particularidades y cómo se dio la evolución en nuestro país y provincia. En efecto, en la Argentina la evolución de este

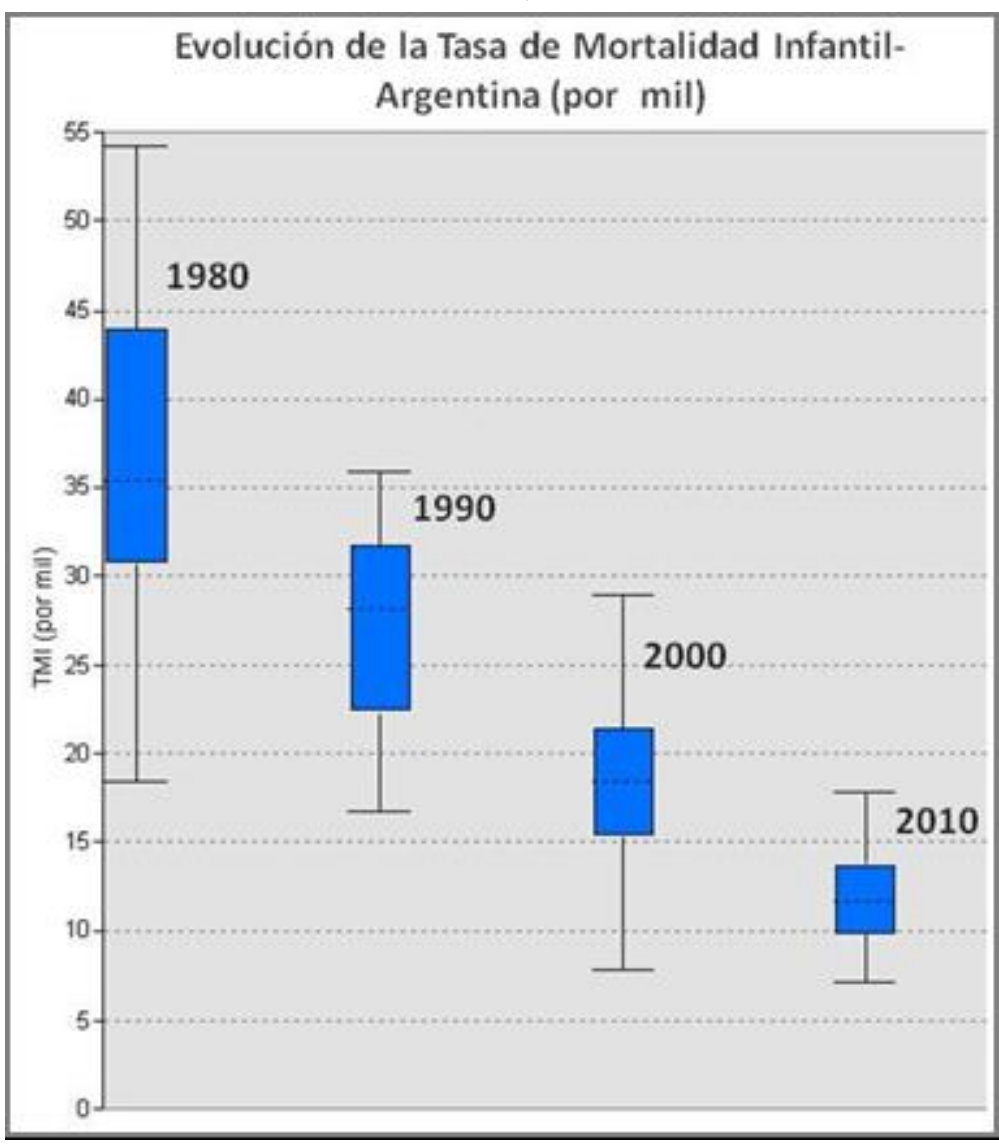

indicador ha sido muy auspiciosa ya que, como en la mayoría del mundo, ha descendido considerablemente. El gráfico que sigue muestra esta declinación en la que se aprecia que los valores máximos cercanos a 55 por mil en 1980 disminuyeron a valores cercanos a 18 por mil en 2010. En cuando a los valores mínimos, éstos se redujeron de 18,5 por mil a 7 por mil en el mismo período.

En el gráfico de caja también se puede observar que la variabilidad o dispersión de los datos perdió intensidad, se puede visualizar que la extensión vertical de cada uno de los gráficos paulatinamente se va reduciendo definiendo un rango cada vez menor, en 1980 registraba 35,7 (diferencia entre el valor mínimo y el valor máximo), mientras que en el

Publicado en formato digital: Mgtr. Vilma Lilian Falcón y Dra. Mirta Liliana Ramirez. DIMENSIONES BÁSICAS DEL DESARROLLO HUMANO: SALUD Y EDUCACIÓN EN LA PROVINCIA DEL CHACO, DIFERENCIAS TEMPORALES Y TERRITORIALES EN LAS ÚLTIMAS DÉCADA Revista Geográfica Digital. IGUNNE. Facultad de Humanidades. UNNE. Año 12. № 23. Enero - Junio 2015. ISSN 1668-5180. Resistencia, Chaco. 
año 2010 el registro era de 10,8. De igual manera el valor medio (indicado con una línea discontinua en el interior de la caja) registra un descenso marcado y constante.

La distribución de este hecho a nivel provincial se puede seguir en los mapas que se han incorporado a continuación, considerando que los valores se han modificado, como hemos dicho, con una evolución favorable para el colectivo involucrado, el propósito es apreciar cómo se visualizan las variaciones espaciales y qué provincias son las que se encuentran en situaciones de mayor y menor bienestar. Los datos se han representado considerando quintiles y nuestra mirada se focaliza sobre el $4^{\circ}$ y $5^{\circ}$ quintil. Chaco, Formosa, Jujuy, Salta Misiones, Misiones, Corrientes y Catamarca son las jurisdicciones que permanecen durante las cuatro décadas en las posiciones menos favorables ya que siempre se ubican en el $4^{\circ}$ y $5^{\circ}$ quintil.

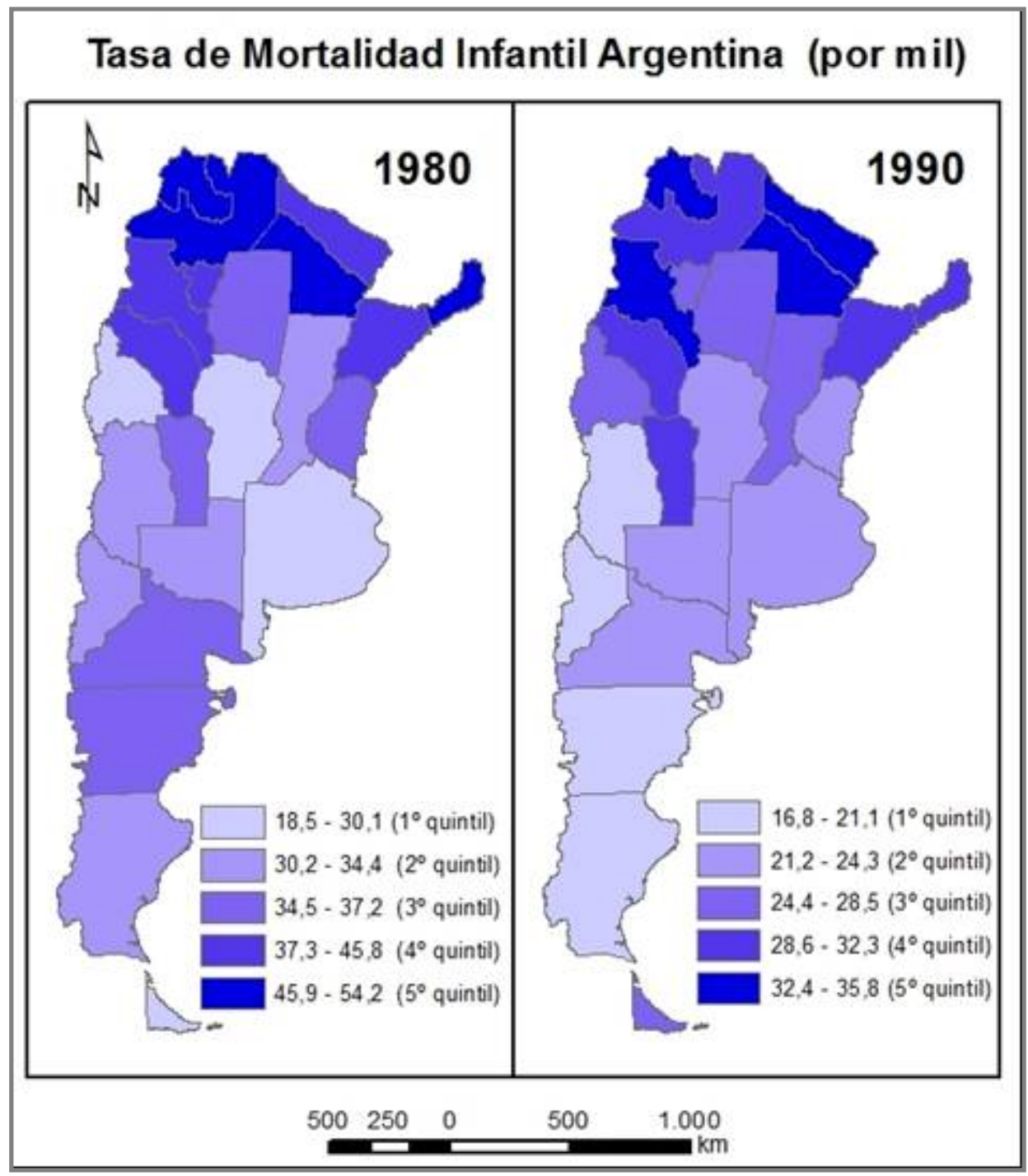

Por otro lado las provincias cuyanas, pampeanas o patagónicas, si bien presentan variabilidad, en ningún caso alcanzan a posicionarse en los quintiles más comprometidos. 
En este sentido son muchas las políticas nacionales que se han desarrollado en el período considerado para achicar la brecha o diferencias entre las provincias, así es que la distancia que separa hoy a las provincias con mayor y menor mortalidad infantil se redujo entre 1980 y 2010 en más de un 30\%.

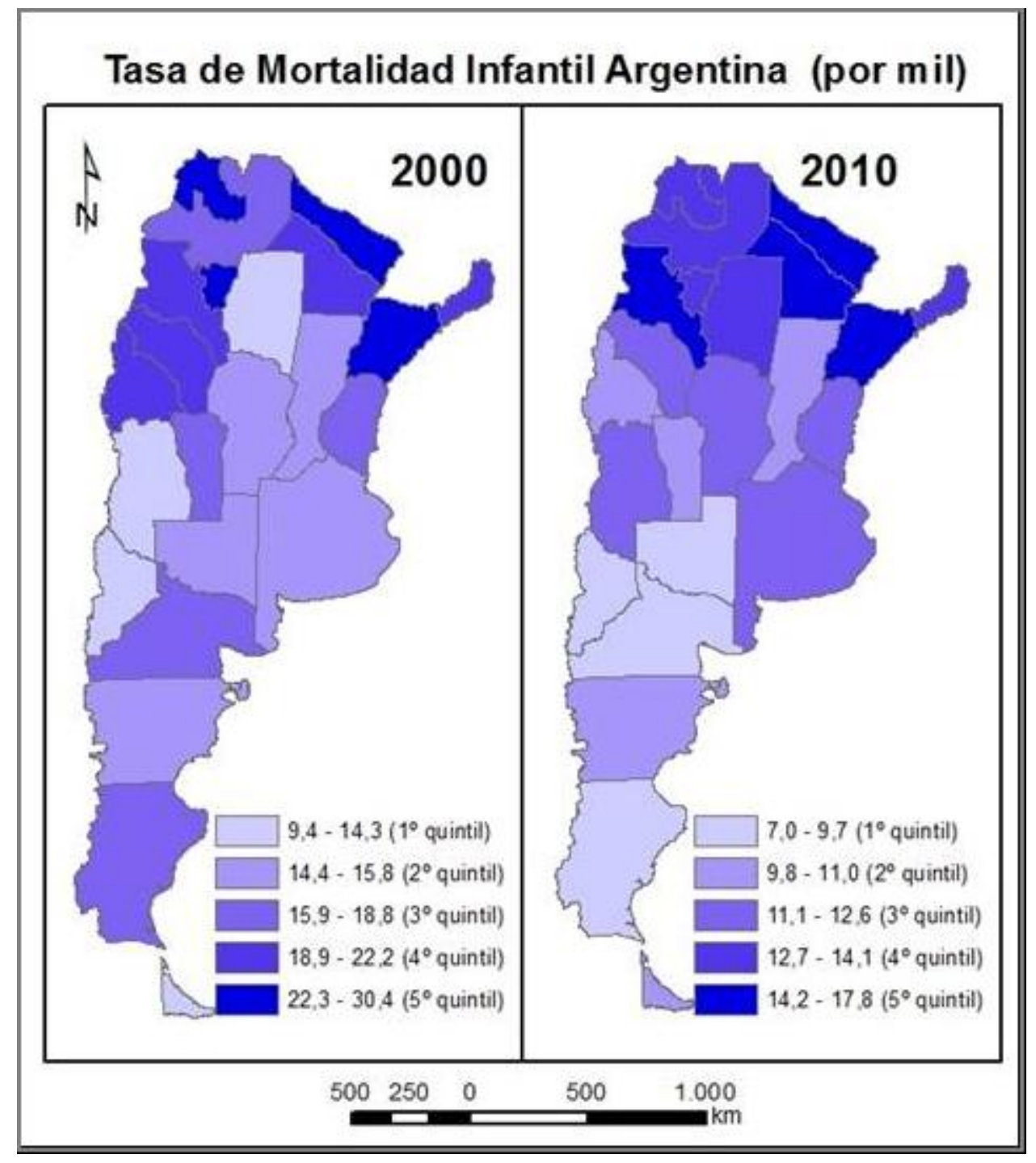

\section{2.- La mortalidad infantil en el Chaco.}

La provincia del Chaco es un distrito que se ha caracterizado por presentar altas tasas de mortalidad infantil. Esta mortalidad, compuesta por la mortalidad neonatal (hasta los 28 días de vida) y la mortalidad posneonatal (desde los 28 hasta el año de vida), tuvo una tendencia descendente importante en las últimas décadas. Esta situación se ha corroborado en trabajos anteriores (Ramirez, 1997:138) en las que se analizó la reducción operada entre los años 70 hasta prácticamente finalizar los '90. En esta ocasión y con la finalidad de dar continuidad al análisis evolutivo apreciamos el comportamiento entre 1980 y 2010. En los gráficos que siguen se visualiza la variación temporal de la mortalidad Infantil y sus componentes Neonatal y Posneonatal en la provincia del Chaco. El primero de los 
gráficos deja al descubierto cómo aporta cada uno de estos componentes al hecho demográfico general, en general se aprecia cómo la mortalidad posneonatal es la que aporta más al descenso de la mortalidad infantil, se visualiza como un hecho anómalo los incrementos de los años 1993 y 1995.

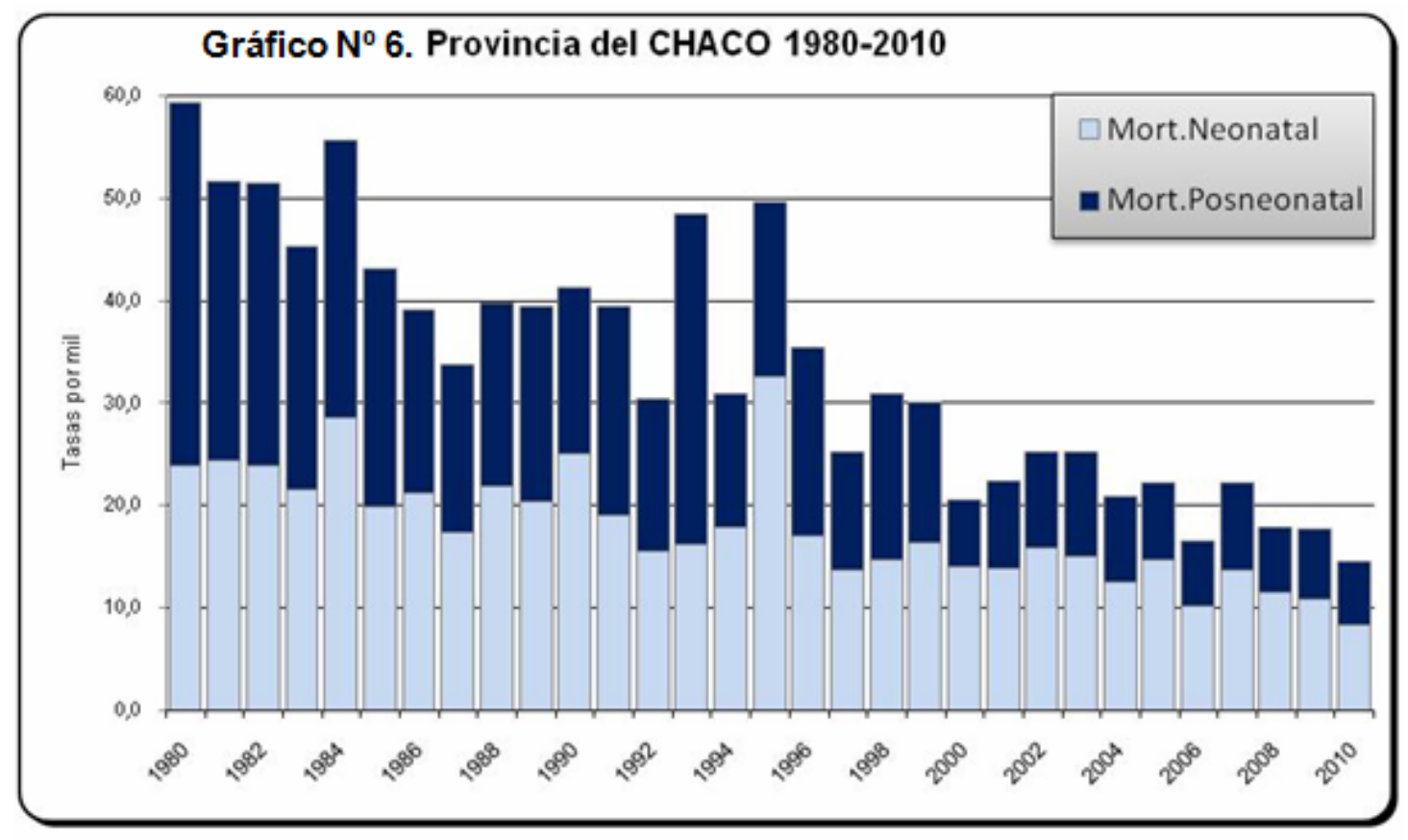

Complementando lo dicho, en el gráfico siguiente se aprecia por ejemplo que las anomalías señaladas se producen, en un caso (1993), por incremento de la mortalidad posneonatal, mientras que en el otro momento (1995) el aumento fue de la mortalidad

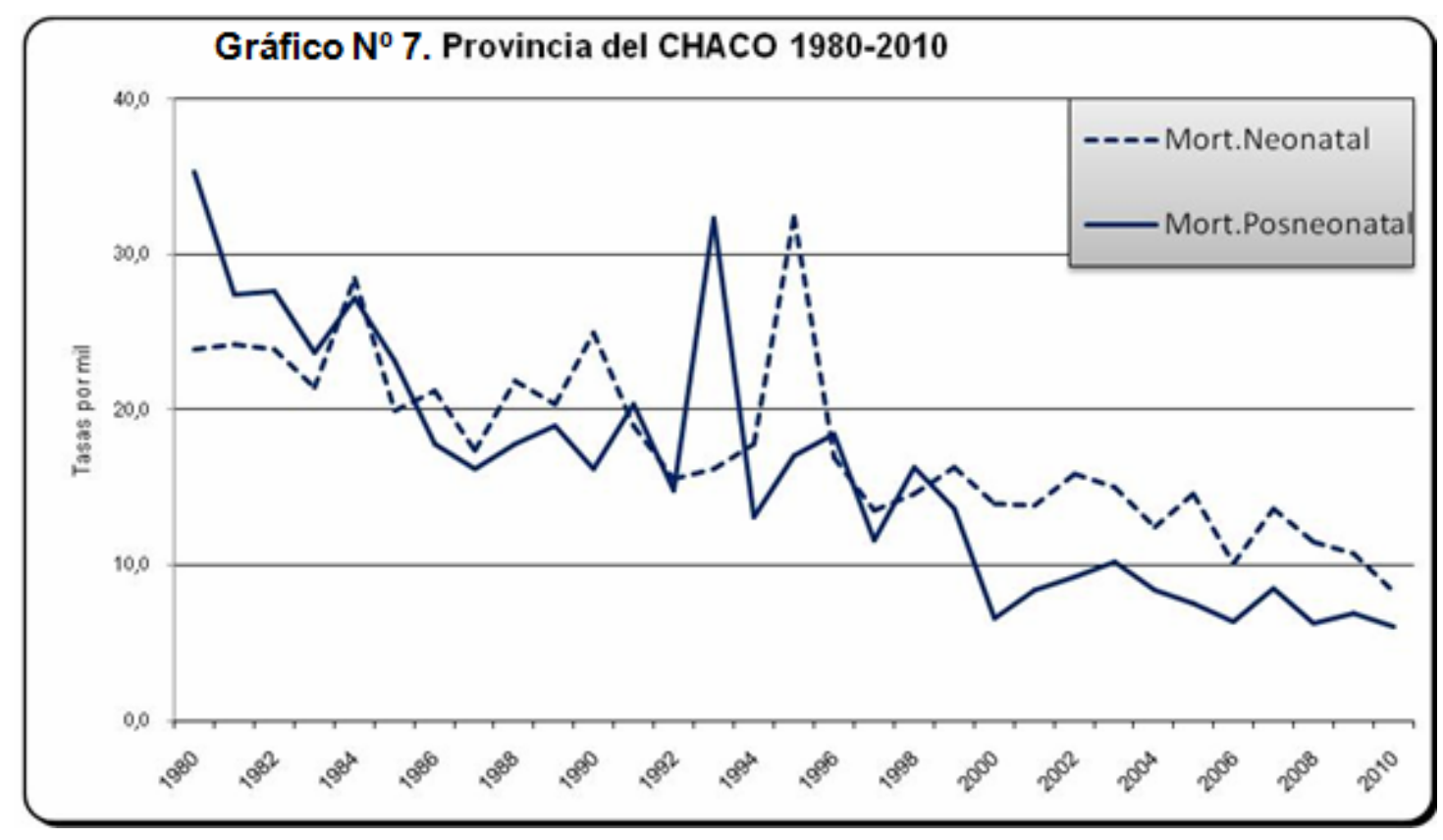

neonatal. Por otro lado se puede visualizar también que el descenso más relevante ha sido el de la componente posneonatal; asimismo después de casi dos décadas de mucha 
variabilidad entre ambos componentes de la mortalidad infantil, a partir de los últimos años de la década de los años '90 se aprecia que la mortalidad neonatal es superior a la posneonatal.

La distribución al interior de la provincia es tan diversa como en el país. Hacia 1980 los mayores registros mostraban áreas con más de 90 por mil en el sudoeste chaqueño. En la década siguiente el mayor registro ya había descendido en casi un 30\% aunque el mismo sector es el que continuaba registrando las tasas más altas, a esta región se sumó la región
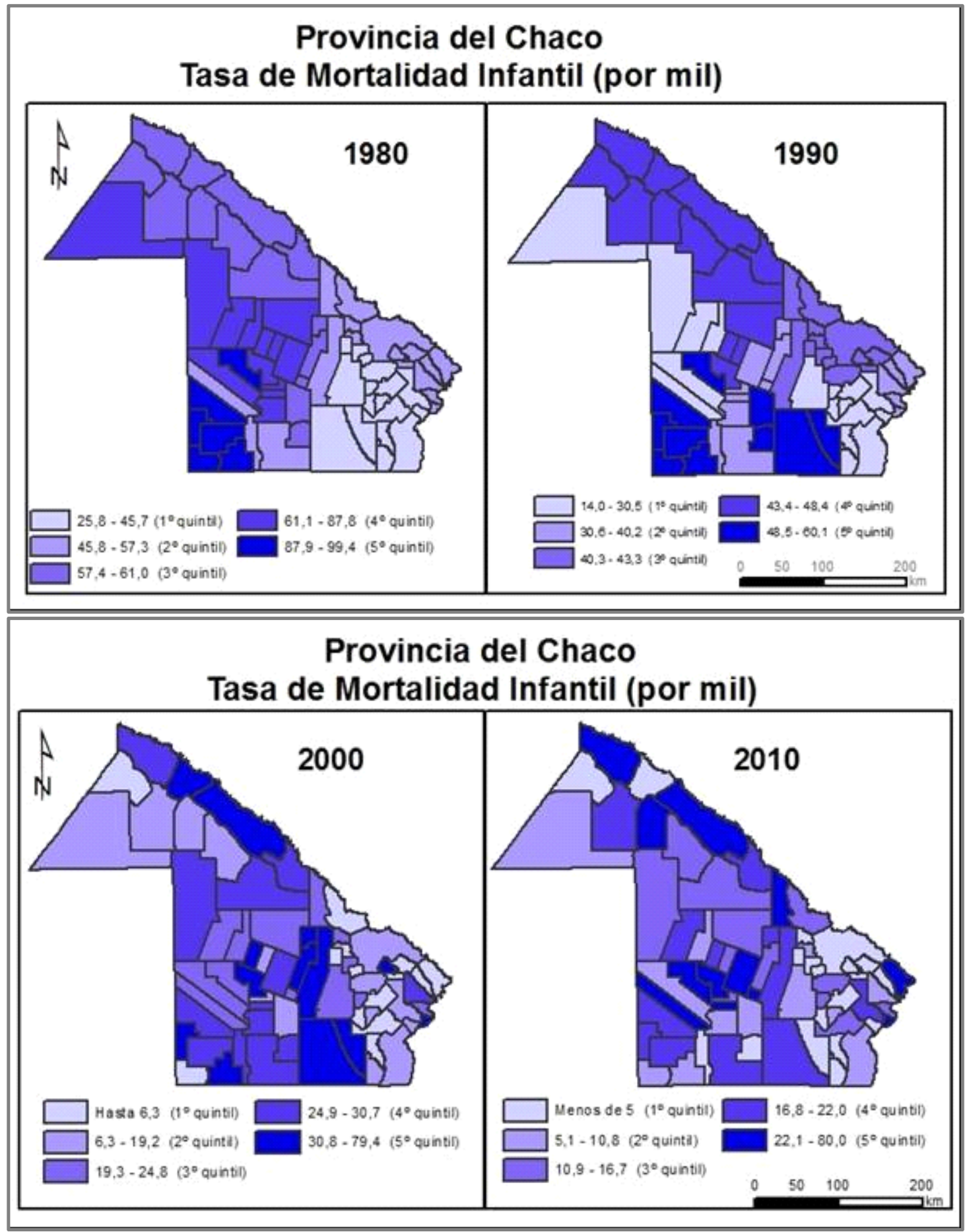

Publicado en formato digital: Mgtr. Vilma Lilian Falcón y Dra. Mirta Liliana Ramirez. DIMENSIONES BÁSICAS DEL DESARROLLO HUMANO: SALUD Y EDUCACIÓN EN LA PROVINCIA DEL CHACO, DIFERENCIAS TEMPORALES Y TERRITORIALES EN LAS ÚLTIMAS DÉCADA Revista Geográfica Digital. IGUNNE. Facultad de Humanidades. UNNE. Año 12. № 23. Enero - Junio 2015. ISSN 1668-5180. Resistencia, Chaco. 
centro-sur (Charadai, Cotelai, Samuhú y Villa Berthet).

La distribución por áreas sanitarias en los años 2000 y 2010 que se muestran en los mapas correspondientes son elocuentes del importante descenso en todas las áreas, más allá de la representación mediante quintiles que permite apreciar siempre las áreas sanitarias más comprometidas, si observamos los valores que contienen los intervalos de clase, podremos distinguir la reducción en las tasas de mortalidad infantil.

Si tomamos en consideración el aporte de la Geografía el bienestar social, surgida de la corriente teórica del Bienestar Humano de la década de los '70 (10), que propone responder a las preguntas ¿quién? (la población investigada), ¿qué? (aquello que da el bienestar a la población), ¿dónde? (la localización de problemas dentro del espacio de estudio) y ¿cómo? (el proceso o mecanismo causal que interviene en la sociedad), podríamos preguntarnos, en concordancia con el análisis realizado en páginas anteriores, ¿quiénes son las personas más desprotegidas? ¿Dónde están? ¿Cuáles son los mecanismos y procesos que originan y perpetúan esas condiciones? ¿Cuáles son las estrategias más adecuadas para reducir al máximo posible esa condición desfavorable?.

Sin dudas, las representaciones apuntan a responder solo una de esas cuestiones. En el caso de la Mortalidad Infantil, no es posible hablar de patrones de comportamiento; en términos generales se advierte una elevada dinámica, una mutación permanente de la posición de las distintas áreas en las diferentes categorías, situación que seguramente dificulta la adopción de medidas o acciones sanitarias focalizadas.

\section{3.- Nacidos vivos según edad de la madre}

Un aspecto importante a considerar al analizar la mortalidad infantil es la edad de la madre. La edad de la madre es un factor que se asocia fuertemente con el posible daño del niño (muerte o enfermedad). Esto ha sido estudiado en diferentes países y verificado para la Argentina en un estudio donde se observa una clara asociación entre determinados grupos etáreos, el bajo peso al nacer y la mortalidad infantil, durante el año 1989 en la Capital Federal y el Conurbano Bonaerense (Ministerio de Salud, 1992). En este trabajo las madres fueron categorizadas en tres niveles de riesgo en relación con su edad:

Alto riesgo - Menos de 20 años.

Bajo riesgo - Entre 20 y 34 años.

Riesgo intermedio - Mayores de 34 años.

En este sentido la provincia del Chaco ha registrado, en todo momento, mayor número de nacidos vivos del grupo de madres de alto riesgo si realizamos comparación con el país.

En el año 2000 en nuestra provincia el porcentaje de madres de menos de 24 años, en los tres primeros grupos de edad considerados, superó el 53\%, frente a menos de un $43 \%$ de la Argentina. Específicamente en el grupo de madres que corresponde a "alto riesgo" Chaco alcanza un $24,5 \%$, mientras que el país registró $15,2 \%$. Sin duda que esta situación es un factor determinante del las tasas de mortalidad infantil más elevadas que se registran en nuestra provincia.

Respecto de las mujeres en riesgo intermedio, en el año 2000 el Chaco registra menos que la Argentina, 11,6 frente a 13,8, situación que actuaría con un factor favorable a la provincia.

Publicado en formato digital: Mgtr. Vilma Lilian Falcón y Dra. Mirta Liliana Ramirez. DIMENSIONES BÁSICAS DEL DESARROLLO HUMANO: SALUD Y EDUCACIÓN EN LA PROVINCIA DEL CHACO, DIFERENCIAS TEMPORALES Y TERRITORIALES EN LAS ÚLTIMAS DÉCADA Revista Geográfica Digital. IGUNNE. Facultad de Humanidades. UNNE. Año 12. № 23. Enero - Junio 2015. ISSN 1668-5180. Resistencia, Chaco. 


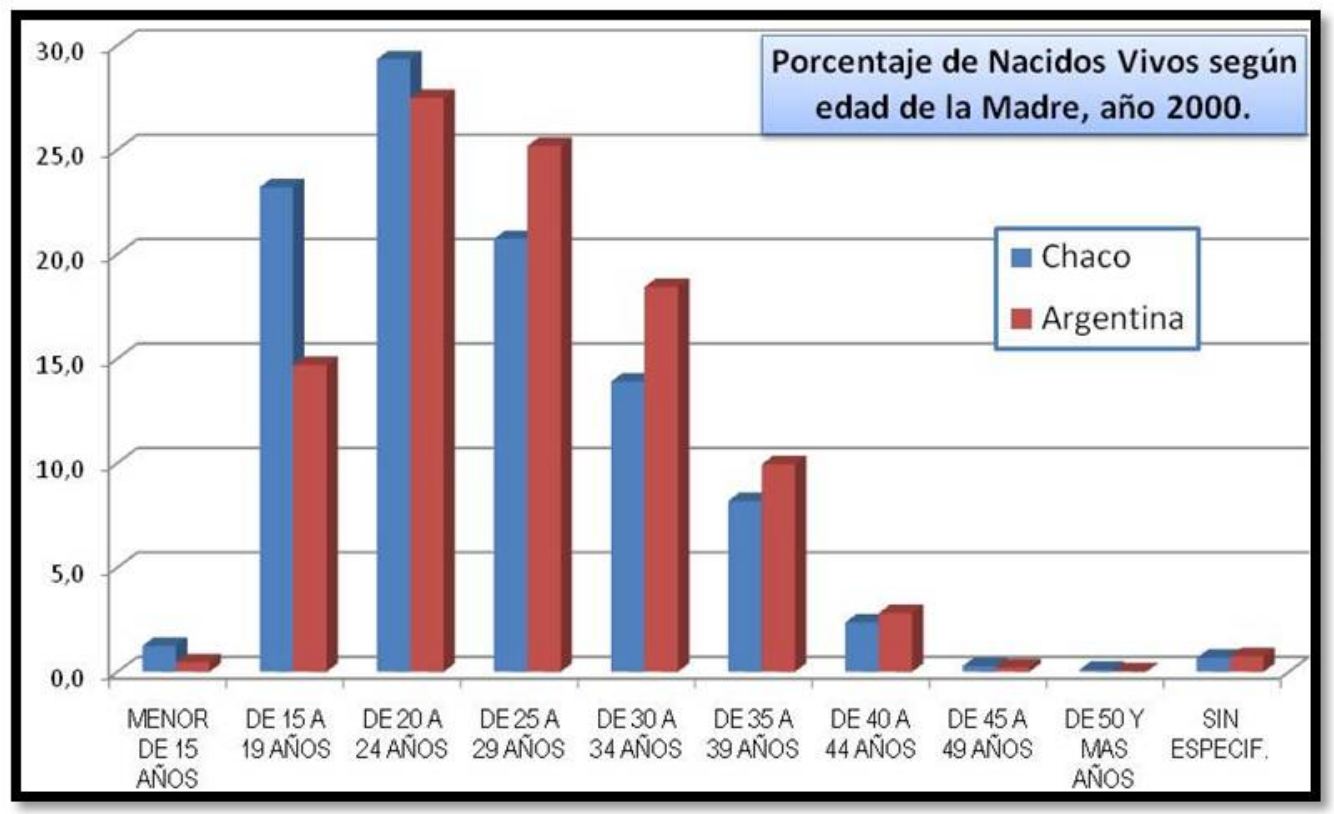

En 2010 la situación se mantiene pero la distancia entre Argentina y Chaco es un poco mayor. En los tres primeros grupos de edad de la madre, el país registró un 39,9\% de los nacidos vivos, mientras que el Chaco alcanzó un 51,9\% (esto significa 12\% de diferencia en 2010, frente a $11,2 \%$ del año 2000). En cuanto a las mujeres en riesgo intermedio, en el año 2010 el Chaco siguió registrando un valor menor al de Argentina, 10,3 frente a 15,7, como ya expresáramos esta situación actuaría con un factor favorable a la provincia.

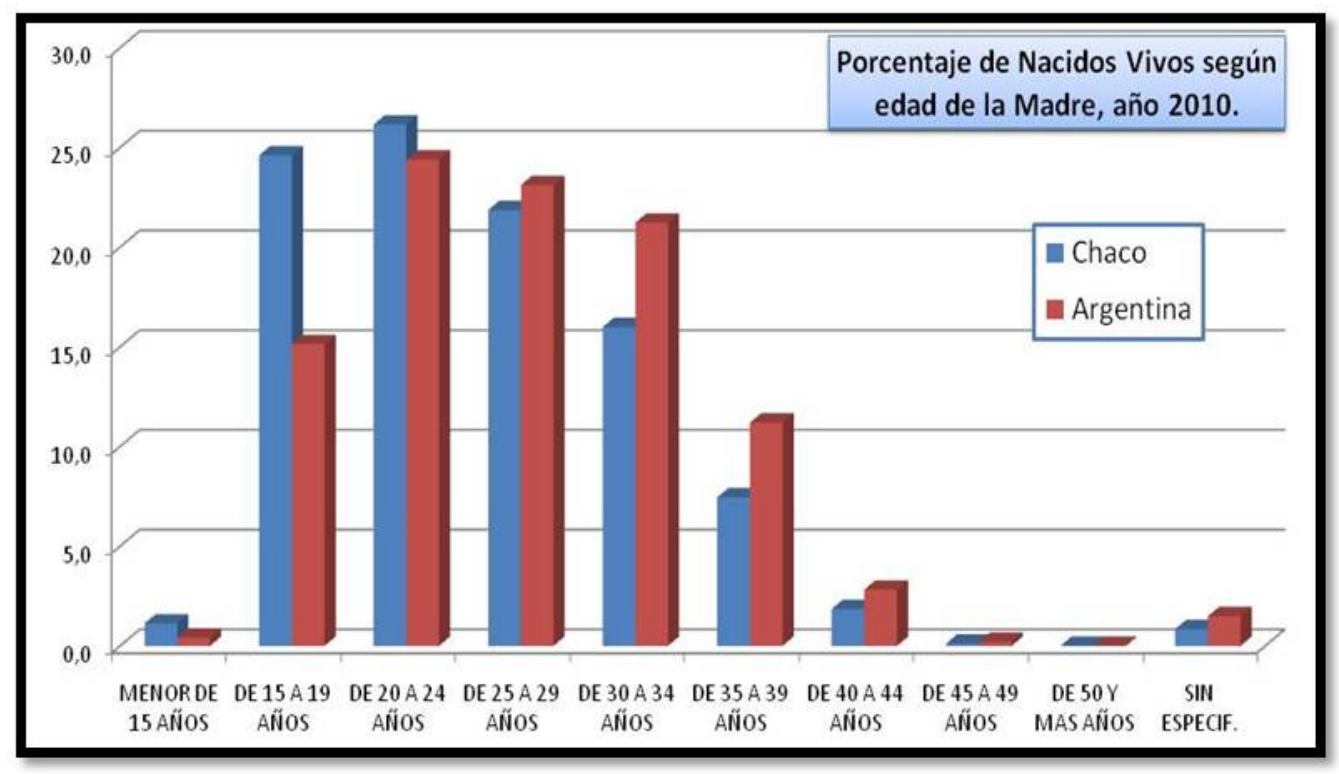

Lo ocurrido en el grupo de madres de más alto riesgo se comporta con pocos cambios respecto del año 2000, mientras que en el Chaco se registró 25,7\%, en Argentina este grupo reunió el $15,6 \%$ de los nacidos vivos. En este sentido la diferencia entre ambos

Publicado en formato digital: Mgtr. Vilma Lilian Falcón y Dra. Mirta Liliana Ramirez. DIMENSIONES BÁSICAS DEL DESARROLLO HUMANO: SALUD Y EDUCACIÓN EN LA PROVINCIA DEL CHACO, DIFERENCIAS TEMPORALES Y TERRITORIALES EN LAS ÚLTIMAS DÉCADA Revista Geográfica Digital. IGUNNE. Facultad de Humanidades. UNNE. Año 12. № 23. Enero - Junio 2015. ISSN 1668-5180. Resistencia, Chaco.

En: http://hum.unne.edu.ar/revistas/geoweb/default.htm 
momentos considerados también se ha incrementado levemente (9,3 en el año 2000 a 10,1 en el año 2010) con mayores registros para el Chaco.

El embarazo antes de los 20 y después de los 35 años, se asocia a un mayor riesgo materno y perinatal. El embarazo en menores de 20 años o embarazo adolescente, además del mayor riesgo biológico que implica, genera una situación de riesgo social para el recién nacido y la madre, siendo un importante problema de salud pública en la mayoría de los países, especialmente para aquellos en desarrollo. El embarazo en mujeres de 35 o más años se asocia a un aumento del riesgo de presentar una serie de patologías propias de la gestación y una mayor frecuencia de patologías maternas crónicas, que traen como consecuencia una mayor probabilidad de muerte materna y perinatal (Donoso et al.2014).

\section{A modo de conclusión}

Nos interesa rescatar un párrafo del Informe de Desarrollo Humano Argentino 2010 en el que se lee: "En relación con la desigualdad en el desarrollo humano, el foco debe trascender los promedios y enfrentar la naturaleza multidimensional del fenómeno, su transmisión intergeneracional y la forma en que se configuran las trampas de desigualdad. La desigualdad no se asienta solo en la apropiación del ingreso, sino también en el acceso inequitativo a las oportunidades educativas y a los servicios de salud, y tiende a reproducirse, de generación en generación, configurando una trampa de difícil escape." (PADH, 2010: 109).

¿Cuál es esa trampa de difícil escape a la que alude el Informe? Refiere a la desigual trasmisión intergeneracional no solo de riqueza material sino también de capital social que facilita las relaciones con otras personas, conocimiento y hasta actitudes y aspiraciones. Cuando no se puede o no se cuenta con los recursos y capacidades la persona puede sufrir los efectos adversos y ello se potencia cuando las carencias se dan desde edades tempranas, especialmente significativas cuando se trata de la salud o mejor dicho de la ausencia de salud. En efecto, numeroso estudios ya han demostrado y continúan sosteniendo que los niños y niñas que padecen de mala salud durante su infancia tienden a ver afectado su desarrollo cognitivo y a obtener logros educativos bajos; a su vez, pobres logros educativos determinan un ingreso bajo y una salud relativamente deficiente en la vida adulta. Por ello, las intervenciones en las etapas tempranas y muy tempranas del desarrollo infantil tienen efectos significativos, no solo en la situación de pobreza e indigencia, sino también en el patrón de desigualdad de un país.

Las provincias del Nordeste Argentino y, en particular, la provincia del Chaco tienen en general- los índices de desigualdad más altos y los índices de desarrollo humano más bajos. La postergación y desigualdad del desarrollo humano en estas provincias es de muy larga data, lo hemos observado en este trabajo con tan solo dos indicadores y aún cuando éstos presentan un ritmo de evolución hacia mejores condiciones debemos seguir insistiendo en hacer visibles cuales son los territorios en los que la sociedad permanece en situaciones injustas.

\section{NOTAS}

1.- Señala Martinez Migueléz (2009) que el ser humano, como todo ser vivo, no es un agregado de elementos yuxtapuestos; es un todo integrado que constituye un suprasistema dinámico, formado por muchos subsistemas perfectamente coordinados: el subsistema físico, el químico, el biológico, el psicológico, el social, el cultural, el ético-moral y el

Publicado en formato digital: Mgtr. Vilma Lilian Falcón y Dra. Mirta Liliana Ramirez. DIMENSIONES BÁSICAS DEL DESARROLLO HUMANO: SALUD Y EDUCACIÓN EN LA PROVINCIA DEL CHACO, DIFERENCIAS TEMPORALES Y TERRITORIALES EN LAS ÚLTIMAS DÉCADA Revista Geográfica Digital. IGUNNE. Facultad de Humanidades. UNNE. Año 12. № 23. Enero - Junio 2015. ISSN 1668-5180. Resistencia, Chaco. 
espiritual. Todos juntos e integrados constituyen la personalidad, y su falta de integración o coordinación desencadena procesos patológicos de diferente índole: orgánica, psicológica, social, o varias juntas. Por esto, el llevar a un ser humano a su pleno desarrollo y madurez, en su realidad integral, constituye la empresa más difícil y ambiciosa que pueda proponerse una persona, una institución e, incluso, una sociedad completa.

2.- La mayor o menor vulnerabilidad está directamente asociada al control que ejercen los individuos y las familias sobre recursos o activos de diferente tipo, cuya movilización permite aprovechar las estructuras de oportunidades existentes en un momento dado, sea para elevar el nivel de bienestar o para mantenerlo ante situaciones que lo amenazan (Katzman, 1999)

3.- Datos publicados en septiembre de 2014 por las Naciones Unidas revelan que las tasas de mortalidad de menores de 5 años han descendido en un $49 \%$ en el periodo comprendido entre 1990 y 2013. No obstante, señalan que pese a que la media del ritmo de descenso anual se ha acelerado, e incluso triplicado en algunos países, este progreso aún está lejos de alcanzar la meta mundial de la reducción de la mortalidad infantil en dos terceras partes para 2015. http://www.who.int/mediacentre/news/releases/2014/child mortality estimates/es)

(cfr: 4.-Según el Informe "Objetivos del milenio 2014" publicado por las Naciones Unidas se señala que en las últimas dos décadas se han logrado notorios avances en todo el mundo en cuanto a la tasa de alfabetización de jóvenes y adultos, así como un descenso simultáneo de la brecha entre la alfabetización de hombres y mujeres, no obstante la cantidad de analfabetos en el mundo sigue siendo alta a pesar del aumento de la tasa de alfabetización.

5.- Falcón, Vilma L. Desarrollo Humano en el Nordeste Argentino (inédito)

6.- PNUD, 2010:40. Informe sobre Desarrollo Humano 2010. En: http://hdr.undp.org

7.- Para 2001 sólo los departamentos de San Fernando, Bermejo, Chacabuco, Comandante Fernández, $1^{\circ}$ de Mayo y Libertad presentaban tasas inferiores a la media provincial

8.-Según datos de la Base REDATAM - INDEC 2010 - en:

http://www.indec.gov.ar/nivel2 default.asp?seccion=P\&id tema=2

9.- El caso extremo al que se alude en el texto, señalado en el gráfico de caja y en el mapa que lo acompaña, corresponde al radio 07 -Fracción 24 - del Municipio de Basail, Departamento San Fernando en el que las dos personas censadas no lee ni escribe constituyendo un $100 \%$ de analfabetismo; dado que el valor se aleja del conjunto se optó por separarlo para obtener el promedio del grupo de 40 radios.

10.-La Geografía del Bienestar es una corriente de pensamiento geográfico dentro de la Geografía Humana que aborda el tema del bienestar social como objeto propio de esta ciencia y se centra en los problemas reales y cotidianos de la sociedad. Nació a fines de la década de 1960 a partir de una corriente liberal surgida de la geografía radical, intentando mejorar la sociedad dentro del mismo sistema. Su principal aporte es brindar orientaciones para la transformación de la sociedad y la obtención de una mejor calidad de vida.- 


\section{BIBLIOGRAFIA}

- Donoso, E., et al. (2014). La edad de la mujer como factor de riesgo de mortalidad materna, fetal, neonatal e infantil. En: Revista Médica Chile vol.142 no.2 Santiago feb. 2014

- Falcón, Vilma Lilian. Componentes del indicador de Desarrollo Humano (IDH) ): la situación de las provincias del Nordeste Argentino en la década del '90. en: http://hum.unne.edu.ar/revistas/geoweb/Geo2/archivos/deshumnea.doc

- Katzman, Rubén, (coord) 1999. "Activos y estructuras de oportunidades: estudios sobre las raíces de la vulnerabilidad social en Uruguay. Cepal, Montevideo.

- Martinez Migueléz, M. (2009). Dimensiones Básicas de un Desarrollo Humano Integral. Polis, Revista de la Universidad Bolivariana, Volumen 8, № 23, 2009, p. 119-138.-

- Ministerio de Salud y Acción Social - Secretaria de Salud - Programa Nacional de Estadísticas de Salud (1992). "Situación Sanitaria de los Menores de 1 año" - Serie 10, Nro.5. Buenos Aires, Argentina.-

- Naciones Unidas - CEPAL -UNESCO (2009). Impacto social y económico del Analfabetismo: modelo de análisis y estudio piloto. Naciones Unidas, Santiago de Chile.

- Organización Mundial de la Salud (OMS). 2014. Estadísticas Sanitarias Mundiales 2014. En: http://apps.who.int/iris/bitstream/10665/131953/1/9789240692695 spa.pdf

- Programa de las Naciones Unidas para el Desarrollo - PNUD (2010). Informe Nacional sobre Desarrollo Humano 2010. Desarrollo humano en Argentina: trayectos y nuevos desafíos. 1.a ed. - Buenos Aires, Argentina.

- Programa de las Naciones Unidas para el desarrollo - PNUD. Informe sobre Desarrollo Humano 2010. Edición del Vigésimo Aniversario. La verdadera riqueza de las naciones: Caminos al desarrollo humano. Ediciones Mundi Prensa. En: hdr.undp.org/es/content/informe-sobre-desarrollo-humano-2010

- Ramirez, Mirta Liliana (1997). Incidencia de factores ambientales en la Mortalidad Infantil en el Chaco. Evolución (1970-1996) y situación actual. En: Primera Jornada chaqueña de Desarrollo Humano. Secretaría de Desarrollo Social. Provincia del Chaco. Resistencia, Chaco.- 